\title{
Community-Based Dental Education at the University of Illinois at Chicago
}

\author{
G. William Knight, D.D.S., M.S., M.S.
}

Abstract: Since 2002, community-based education at the University of Illinois at Chicago College of Dentistry (COD) has evolved from non-existent to a robust program that is an essential component of the predoctoral program. As part of the college's curricular innovation, community-based education has demonstrated alignment of the COD's mission with that of our parent institution, contributed significantly to student learning and preparedness, and enhanced clinic experiences and revenue. Student interest and support have been and continue to be enthusiastic and valued. The faculty has been generally supportive, but properly focused on demonstrated student learning outcomes. This faculty observation and evaluation, supported by evidence, has resulted in the faculty's rethinking traditional teaching and learning strategies, allowing innovative educational changes.

Dr. Knight is Executive Associate Dean for Academic Affairs, College of Dentistry, University of Illinois at Chicago. Direct correspondence and requests for reprints to Dr. G. William Knight, College of Dentistry, University of Illinois at Chicago, 801 South Paulina Street, 102A DENT, MC 621, Chicago, IL 60623; 312-996-3576; gwknight@uic.edu.

Keywords: community-based dental education, dental school finances, clinical education

$\mathrm{T}$ The University of Illinois at Chicago (UIC) promotes a rich culture of service-learning - a commitment that extends to every college in the university. Indeed, the UIC Mission Statement includes these service-related goals within its mission: "to address the challenges and opportunities facing not only Chicago, but all Great Cities of the $21^{\text {st }}$ century, as expressed by our Great Cities commitment" and "to foster scholarship and practices that reflect and respond to the increasing diversity of the U.S. in a rapidly globalizing world.” The UIC Great Cities Program is an integral part of university life, as reflected in these words: "As the Chicago area's largest university, UIC has a responsibility and unique opportunity to contribute to the well-being of urban life."

The university's community commitment is rooted in the deep tradition of Hull House, founded in 1889 by Jane Addams. Hull House, which is located on the UIC east campus, was built on several basic values that continue today: the fundamental dignity of all; poverty and the lack of opportunity breed problems; and to understand community problems, one must live in and embrace the community. These tenets are evident in UIC's educational, research, and service programs.

The UIC College of Dentistry (COD)'s Mission Statement is "to promote optimum oral and general health to the people of the State of Illinois and worldwide through excellence in education, patient care, research, and service." To carry out this mission, four of the COD's nine institutional goals are related to community service-learning programs:

1. To provide patient-centered care that is comprehensive and compassionate for a culturally diverse population;

2. To address community and regional health care needs through outreach initiatives, educational programs, and consultative and referral services;

3. To maintain a leadership role in forming health care policy at the university, state, and national levels;

4. To value and seek diversity in students, staff, faculty, and patients.

Related to its mission and goals, the COD has a set of competency statements, many of which are related to community programs: "A graduate of the predoctoral (D.D.S.) program at the University of Illinois at Chicago College of Dentistry will be competent to:

1. Apply the fundamental principles of the behavioral sciences as they relate to patient-centered approaches for promoting, improving, and maintaining oral health;

2. Employ the interpersonal and communication skills necessary to provide oral health care to a diverse patient population and to function in a multicultural work environment;

3. Evaluate various models of oral health care management and delivery; and 
4. Apply the principles of ethical reasoning and professional responsibility as they relate to patient care and practice management.

The COD's mission statement, goals, and competencies were influenced by three important external events in 2002. The closure of the Loyola and Northwestern dental schools changed the Chicago and state dental educational infrastructure; the COD recognized that it had not taken advantage of the extent, diversity, and richness of Chicago; and the college needed to respond to the announcement of the launch of the Pipeline, Profession, and Practice: Community-Based Dental Education program. The convergence of these events provided a strong impetus for the development of a community-based dental education program. This chapter describes the elements of the program and the environment that has helped it become successful.

\section{Faculty and Student Support}

From faculty surveys and discussions, it is clear that the majority of the faculty enthusiastically support the extramural program and that this has been true from the beginning. Although a small group of faculty members continues to have concerns about the amount of time students spend in the community rather than the extramural program per se, major concerns have been addressed in several areas.

Value to learning. Some faculty members have correctly noted that the COD patient population is also largely underserved and have questioned how much additional value students gain in practicing in community-based settings. The COD's position is that the extramural program adds value in ways that go beyond caring for the underserved. First, the program takes students to where patients live, providing them firsthand experience with social barriers to care (e.g., transportation, customs, values, and economics). Second, students gain valuable practice management experience (e.g., clinic operations and finances) in those settings. Third, practicing in community clinics provides students with their only opportunity to work consistently with dental assistants and other clinic staff. Fourth, students gain insights into the policies and politics of clinic community constituencies and governing boards. Fifth, they treat many more patients in a clinic session than in the school-based clinic and gain the skills and confidence that come with more clinical experience. Sixth, the student to faculty ratio is $1: 1$ to $1: 2$ in community clinics versus 1:6 in COD clinics, providing students with more opportunity to work closely with experienced colleagues. Finally, students help to reduce access disparities by providing care to more patients in community clinics.

Quality of learning. Some faculty members have also expressed concern about the quality of students' educational experience in community clinics because of perceived inadequacies in community clinic preceptors (research and teaching experience), facilities, and equipment. To address this issue, the COD holds annual conferences for preceptors and college faculty that focus on teaching and learning issues. However, the COD does not want the clinics to create "mini-UICs." Indeed, we value the experience students gain in working in different delivery systems.

The college also instituted meetings between site preceptors and UIC clinic leaders at the COD and arranged for COD department heads and selected faculty members to visit community clinics. These visits were successful in changing many faculty members' opinions about the community program. Most were impressed with the clinic preceptors' energy, enthusiasm, and clinical expertise and with the quality of facilities and equipment.

The greatest influence in addressing faculty skepticism has been the students. With few exceptions, they are overwhelmingly enthusiastic and consistently support the value of clinic rotations to their understanding of underserved patients, communities, and the dental care delivery system and to their personal professional growth. In fact, we urge schools that are contemplating starting community education programs to use students' observations to gain faculty understanding and support.

Student preparedness. In planning the extramural program, the COD Curriculum Committee recognized that significant changes were needed in the predoctoral program. Specifically, students needed to be approaching clinical care independence at the end of the third year. To this end, a summer term was added between the first and second years to provide more teaching time. In addition, faculty members reviewed the content and sequence of all courses and identified topics that were redundant or needed reinforcement. The end result of this review was the creation of eleven comprehensive care courses, one for each semester of the curriculum. These courses 
subsumed many one credit hour courses (e.g., ethics, behavioral science, practice management) and many preclinical and clinical courses. Some material was also resequenced within and between courses (e.g., restorative and pediatric dentistry). Each year the curriculum is reviewed and continuously improved.

Clinic revenue. Many faculty members were concerned that COD clinic revenues would decline if seniors spent significant time in community rotations. To address this issue, the COD changed the organization of the clinic program from a discipline-based to a comprehensive care-based system and at the same time eliminated all numerical clinical requirements except for attendance. These two changes resulted in a significant increase in student productivity and revenues.

In 2004-05, the extramural experiences began with a small group of students spending a combined total of 120 days in community clinics. The total number of student off-site days grew to $1,830,3,350$, and 4,110 over the next three years, respectively. This number's falling to 3,730 in the fourth year (2008-09) was because there were fewer students in the class. Even so, COD clinic revenues increased from $\$ 2.66$ million in 2004-05 to $\$ 4.52$ million in 2008-09. In large part this is because of the greater productivity of students since the COD does not receive any income from community clinics and practices. Although each year faculty members are made aware of changes in student productivity, some continue to argue that the college would be better served financially if senior students, known to be the most productive, did not spend time in community rotations.

As far as students' reactions, while a handful have expressed some concerns, overall student support for the extramural programs is extremely strong. This is especially true of students who are in the $2 \times 2$ program, spending most of the year rotating between the COD (two weeks) and community clinics (two weeks). Until the 2010-11 year, there were more green-lighted students eligible for the 100-day program than capacity to accommodate them.

Initially, some students were concerned that residency programs to which they were applying might not value these "outside" experiences. However, this year eighteen of the twenty students seeking general dentistry residency training were successful in obtaining positions, so this issue is no longer a concern. Likewise, predoctoral applicants to UIC are fully informed of the extramural program, and the ability to participate in it seems to be an important reason for their selecting the COD.

\section{College of Dentistry Finances}

Until three years ago, faculty and staff members viewed the COD as a reasonably secure place to work, and the mix of state funds, clinic revenue, alumni support, and research grants provided adequate funding. However, the recession and the state's inability to devise sound financial policies have had a profoundly negative impact on all state-funded activities, especially higher education. With less than two weeks left in the 2010 fiscal year, the University of Illinois received $\$ 300$ million less in state appropriations than was budgeted. In that fiscal year, the COD was thus required to eliminate $\$ 1.8 \mathrm{M}$ from its budget, and this reduction was made permanent in 2011.

These reductions have led non-tenured and clinical-track faculty members to be concerned about their positions. While the dean has managed through these budget problems by eliminating some non-faculty positions and increasing clinic revenues, faculty members remain concerned about the college's finances and have made many constructive suggestions on how to improve college finances. Clearly, the COD cannot continue to balance the budget through tuition and fee increases. In this rather grim context, it is a plus for the extramural program that it contributes significantly to the financial standing of the college.

For FY 2010 no faculty positions were terminated, but 2.8 clinical faculty positions that became available from retirements were not filled. For FY 2011, 4.8 non-tenured clinical faculty positions (two full-time) were eliminated, but none were biomedical or behavioral scientists. Due to this and previous budget reductions, non-faculty staff have been cut to the functional minimum, and further reductions would likely have a detrimental effect on patient care and student learning. With respect to faculty compensation, until the last two years salary increases were in the 1.0 to 2.5 percent range. In fiscal year 2010, salaries were frozen, and this year they were not only frozen, but faculty members earning more than $\$ 30,000 /$ year were required to take four unpaid furlough days, and deans and senior administrators were required to take ten unpaid furlough days. In 
the long term, most faculty members assume salary increments will be small, if they occur at all.

\section{Dental School Clinics}

UIC's community-based dental education program has had significant positive effects on our management of the college's preclinical laboratories and clinics. A basic educational tenet is that all practice skills should be presented in the actual environment in which they are used (i.e., dental clinics). Beginning in the 2011 fall term, traditional preclinical laboratories will no longer be used at the COD, and all clinical education, whether simulated or actual patient care, will occur in patient care clinics. This approach adds relevance to learning and maximizes utilization of physical resources. It also means that \$2.0 million were saved in simulation laboratory update and renovation expenses. This approach is only feasible because the fourth-year extramural program made more chairs available for first- and second-year students.

Advantages for the school's clinics can be seen in the way the clinics are organized to support the curriculum. Currently at UIC, first-year students spend one to two days per week in school clinics; second-year students spend one day per week in direct patient care and two days in simulated implant and advanced prosthodontic care; third-year students provide patient care five days per week; and seniors split their time (fifty to 100 days) between the COD clinics and community clinics. The school clinics, with the exception of pediatrics and orthodontics, are designed to provide comprehensive care, and all students (years 1 to 4 ) are organized into three group practices, each staffed by six faculty members (two general dentists and one prosthodontist, one periodontist, one endodontist, and one urgent care specialist). Pre-patient care faculty members are also assigned to each clinic. Exodontia is considered a part of general practice after students complete a four-week surgery rotation in the third year, while simple and surgical extractions are supervised by general dentists.

Each group practice has fifty-six dental operatories, and another sixty-eight chairs are available for preclinical training. The latter facility will also become the clinical home of a new international student program. The predoctoral pediatric clinic has sixteen operatories. Students working in the group practices schedule their own patient appointments.
In the radiology, pediatric dentistry, and oral surgery rotations, patients are scheduled by clinic staff.

The COD does not have numerical procedure requirements since the faculty considers numerical requirements antithetical to comprehensive patient care and effective student learning; however, students must attend scheduled clinics. To ensure diversity of experiences, the managing partner (a faculty member) of each group practice monitors the performance of individual students. The staffing ratios (faculty to students) in the preclinical setting are 1:9 and in the clinic are 1:6. For every full-time faculty member there are two part-time faculty members. Since each managing partner is responsible for ensuring that patients are well treated, they have created a buddy system in which students are paired by alternating two-week extramural assignments. Student A is responsible for Student B's patients for the two weeks Student B is away and vice versa. In most cases, Students A and B cover each other for the entire rotation schedule.

With the budget cuts and the loss of faculty positions, the use of volunteer faculty became an issue that had to be considered. The argument against using volunteers is that they may be viewed as taking the positions of paid part- and full-time clinical-track faculty; also, some volunteer faculty may have attendance problems. For these reasons, the COD does not plan to use volunteer faculty. Fortunately, the extramural program has reduced the need for faculty in the clinic, so that several were moved to the preclinical program. This shift-made possible by the community-based program - has allowed the college to more effectively cope with state budget reductions.

\section{Elements of the Community-Based Program}

The overall forty-four month curriculum at UIC is divided into eleven semesters, and some aspect of clinical care has been incorporated into each year, building up to students' participation in the community-based dental education program in their senior year. The first year focuses on the biomedical sciences, including anatomy, histology, and biochemistry. Through the use of patient care portfolios, the biomedical sciences are linked to applied clinical issues and the concepts and processes of evidence-based practice. In its new unified curriculum, biomedical, behavioral, and clinical sciences 
are integrated through the use of patient scenarios. Students are challenged to make evidence-based decisions based on the best available information. They are also introduced to public health, epidemiology, statistics, and the concepts of a healthy orofacial complex. Students begin clinical training in their first semester, concentrating on patient assessment and examination. The courses integrate material from all clinical departments, based on the educational philosophy that teaching by discipline independent of comprehensive general patient care is the antithesis of an effective predoctoral program.

By the end of the third year, students have gained broad experience in restorative, pediatrics, periodontics, endodontics, exodontia, urgent care, applied behavioral and biomedical sciences, and imaging. Behavioral skills are developed in the ethics and communications curriculum running from the first to the third years. The biomedical sciences are updated through the continuing use of patient scenarios. By the end of the third year, the managing partners certify that students have the competence, social maturity, and problem-solving skills to work effectively in extramural clinics prior to their assignment to partner clinics.

\section{Organization and Curriculum}

In their first year, students participate in a tenhour per semester oral health education program for elementary school children. No other formal extramural experiences occur until the fourth year, but students run a voluntary program providing care to homeless people. Students make appointments, maintain records, provide care (exodontia, restorative, and temporary removable appliances), and organize supplies under the supervision of volunteer faculty members. This voluntary clinic is open two days a month, and students from all four classes participate in it.

In the fourth-year course Community-Based Education (DADM 325), selected students are offered the opportunity to participate in the twelve-month, 100-day 2 X2 program, in which they spend three months at each of the four participating clinics. Over the past three years, a total of forty-one students have completed the $2 \mathrm{X} 2$ program. Students who are not selected for the 100-day program spend fifty days in the community program, split evenly between two community sites. Each year, a few seniors are not ready for the full community experience, but none have spent less than thirty days extramurally.
Two events in the third year have prepared students for the senior year extramural experience. First, the curriculum for the DADM 325 course includes a detailed description of the fifty- and 100-day programs and an overview of the seventeen extramural sites. In the second event, students and community partners participate in an orientation session. Each community partner gives a ten-minute overview and answers questions; these presentations are followed by an open house in which students meet with clinic preceptors and representatives. Students are assigned to sites primarily based on their personal preferences. Each student is asked to select a first and second choice for each rotation. To the extent possible, students are given their first choice. Usually, two students are assigned to each site for two weeks.

The community-based dental education program at UIC is not housed in a specific department. Program leadership is at the dean and associate dean levels, but is, of course, within the domain of faculty governance bodies (e.g., the Curriculum Committee). It is important to stress that patient care is not the only educational goal of the extramural program. Rather, the COD wants students to experience patient care in multiple safety-net delivery settings, including federally qualified health centers (FQHCs), federal service clinics, closed panel practices, philanthropic clinics, and fee-for-service private practices. Students are also expected to participate in the policy-setting boards of community partner organizations and to gain firsthand experience with initiatives to address access disparities.

Since the COD does not have numerical procedure-based graduation requirements, the services students provide at community sites are not counted toward some numerical goal, but attendance is mandatory and several forms of assessment are used. The college tracks extramural and COD patient care experiences to ensure that each student has a wellrounded clinical education. Beyond the faculty/preceptor evaluation, each student is required to prepare a reflective essay in a "What, So What, Now What" format. At the conclusion of each rotation, there is a debriefing session. The issues discussed include merits of the site, experience gained in patient care, interactions with mentors, and organization of the business. These sessions are led by students and are valuable for both the college and the site. Using the same performance evaluation criteria as the college, clinic preceptors also provide a written assessment of each student at the end of each two-week rotation and the total extramural program. Annually, the pre- 
ceptors and managing partners meet to discuss the program and review policies and procedures.

The COD currently has partnerships with seventeen community sites, all of which have formal affiliation agreements with the college. The COD provides insurance for students and site preceptors when they are supervising students. However, the college has no ownership interest in any sites and does not receive any direct income from sites. The possibility of revenue-sharing was discussed with the FQHCs, but their state-negotiated encounter rates are too low to support it.

\section{Community-Based Program Finances}

The community program is the responsibility of the Office of Prevention and Public Health Sciences, headed by an associate dean assisted by 1.7 FTE staff positions. The combined salary and benefits for this group are about $\$ 430,000$.

Only one site requires travel and lodging funds, but fortunately, the COD shares these costs with the UIC College of Medicine. The nominal fee for housing is $\$ 100 /$ student/week, and students are reimbursed $\$ 0.43 /$ mile for travel. At this time, the college covers these expenses from a state grant. On occasion, the college leadership has discussed with the community clinics the possibility of their covering students' travel and per diem expenses, but in spite of supporting data that students contribute positively to clinic net revenues, none have been willing to contribute to these expenses. The faculty members visiting sites are paid for travel expenses; so far, those visits do not require overnight lodging.

Annually, the COD holds a one-day conference for clinic preceptors and COD faculty. A special halfday event is also organized for preceptors, students, managing partners, and key administrators as a capstone debriefing for the 100-day program. Preceptor travel expenses are not reimbursed by the college, but they do receive a modest lunch.

\section{Program Outcomes and Continuing Assessment}

Student support for the program remains strong. The community experiences are valued by students, who enjoy the relative clinical independence compared to what they experience in the COD clinics. With a preceptor to student ratio of 1:2, preceptors continue to care for their own group of patients and give most students a relatively broad range of authority. Students also value having a full-time chair-side dental assistant and seeing four to eight patients per day, seeing it as a welcome experience for transitioning to private practice. Students have pressed for better methods of communicating with the group practice managing partners and, specifically, want access to their electronic patient records. Because of HIPAA concerns, the COD cannot provide students with offsite access to the patient database, but the buddy system is expected to ease this communication problem.

The dean continues his strong support for the program and belief that it is fundamental for a firstclass education. However, he must balance financial, alumni, and political factors to ensure the continuing support of key stakeholder groups and the college's stability, so he requires an open and accurate assessment of the program each year.

In terms of faculty support, the budget reductions have caused some to renew arguments that it makes no sense to have the most productive students offsite, making money for someone else. However, a recently completed financial analysis shows just the opposite for the 100-day program: the college is better off financially and students have more and better clinical experiences because of the extramural program.

Most clinical faculty members believe that the extramural program enhances students' confidence, clinical efficiency, and exposure to diagnostic, preventive, and direct restoration skills. Some still have concerns about students' clinical experience with more advanced services; however, six years of extramural data demonstrate that the number of advanced procedures per student has remained steady and in some areas has improved. The reality is simply that, in the current economic situation, COD patients do not have the economic wherewithal to support expensive dental care options.

It is without question that the curricular and clinical changes enabled by the community-based program have profoundly impacted student productivity and, as a result, increased the college's clinical revenue. In the 2003-04 academic year, prior to the start of extramural education, third-year students produced an average of $\$ 8,015$ per year and fourth-year students $\$ 20,834$. For the 2009-10 academic year, third-year students produced an average of $\$ 26,074$ and fourth-year students $\$ 26,290$. These are 300 percent and 20 percent increases in third- and fourth-year student productivity, respectively. Further, it is critical 
to remember that the fourth-year student gain occurred even though students averaged sixty-five fewer days in COD clinics. In terms of average daily production per student, in 2003-04 third- and fourth-year students produced $\$ 36$ and $\$ 94$ per day, respectively. In 2009-10, those rates increased to $\$ 121$ and $\$ 159$ per day, respectively. Finally, total predoctoral clinic revenues increased from $\$ 2,955,000$ in 2003-04 to $\$ 4,750,000$ in 2009-10 (2010 dollars).

Over the past four years, only two students (out of more than 270) failed to graduate on time. Along with increased clinic productivity and revenues and slightly improved National Board Dental Examination scores, the data strongly support the conclusion that the extramural program has had a positive impact on students and the college. The data on the impact of the community program on careers are limited, but at least eight of last year's graduates are now employed in partner sites.

\section{Conclusions}

Prior to 2004, the UIC College of Dentistry had no extramural program. Over the ensuing seven years, its program has grown significantly, and now every student spends at least thirty days in community clinics, most spend fifty days, and nearly 35 percent spend more than eighty days. In addition to the increases in student clinic productivity and clinic revenue, tangible program outcomes include the following: greatly expanded student patient care experiences; a heightened student awareness of access issues; student participation in various health care delivery models; curricular innovations leading to greater efficiency and effectiveness of pre-patient care programs; and the freeing up of over 10,000 square feet of space, which was reallocated to basic and clinical research programs.

The development of the extramural program challenged the college's faculty to rethink traditional learning strategies and programs. Without this willingness to take risks, the college could not have made the community-based program a core part of the clinical program, and students would have been deprived of a valuable educational experience. 